\title{
Nevus sebaceous
}

\author{
Ana Sofia Lopez MSc MD, Joseph M. Lam MD
}

Cite as: CMAJ 2019 July 8;191:E765. doi: 10.1503/cmaj.190030

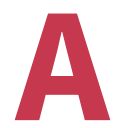

n otherwise healthy 17-month-old girl presented with a well-defined, yelloworange oval plaque with alopecia on her left scalp since birth (Figure 1). It had been growing proportionately with her. The child's plaque was consistent with a nevus sebaceous. Followup was planned for age 4-5 years, when the child would be able to participate in the decision for its removal.

A nevus sebaceous is a congenital hamartoma usually found on the head and neck, with a prevalence of $0.3 \%$ in newborns. ${ }^{1}$ It consists of hyperplasia of the sebaceous glands with overlying alopecia, as mature hair follicles are absent. The differential diagnosis includes aplasia cutis congenita, an epidermal nevus and a mastocytoma. In infancy, it is usually smooth but may also be raised and verrucous, representing papillomatous hyperplasia and immature hair follicles. During puberty, because of hormonal influence on sebaceous and apocrine glands, it can undergo rapid growth and can become more verrucous. ${ }^{2} \mathrm{~A}$ larger nevus sebaceous can also have associated eye and neurologic anomalies (nevus sebaceous syndrome). ${ }^{3}$

Over time, both benign and malignant growths can occur within the nevus sebaceous. ${ }^{2,3}$ The necessity and timing of excision is controversial. In the past, the incidence of basal cell carcinoma was thought to be as high as $22 \%$; however, this was an overestimate due to misdiagnosis of secondary adnexal growth, such as benign trichoblastomas and basal cell hyperplasia. ${ }^{2,4}$ Recent studies have shown low rates of malignant transformation, ranging from $0 \%$ to $0.8 \% .^{3-5}$ The benefits of early excision of a nevus sebaceous should be weighed against the risks associated with general anesthesia as compared with later excision under local anesthesia. Regular follow-up for observation of a nevus sebaceous is another reasonable option. Determination of observation versus excision should involve shared decision-making between the physician, parent and patient.

\section{References}

1. Barkham MC, White N, Brundler MA, et al. Should naevus sebaceus be excised prophylactically? A clinical audit. J Plast Reconstr Aesthet Surg 2007;60:1269-70.

2. Moody MN, Landua JM, Goldberg LH. Nevus sebaceous revisited. Pediatr Dermatol 2012;29:15-23.

3. Rosen H, Schmidt B, Lam HP, et al. Management of nevus sebaceous and the risk of basal cell carcinoma: an 18-year review. Pediatr Dermatol 2009;26:676-81.

4. Cribier B, Scrivener Y, Grosshans E. Tumors arising in nevus sebaceus: a study of 596 cases. J Am Acad Dermatol 2000;42:263-8.

5. Santibanez-Gallerani A, Marshall D, Duarte AM, et al. Should nevus sebaceus of Jadassohn in children be excised? A study of 757 cases, and literature review. J Craniofac Surg 2003;14:658-60.

\section{Competing interests: None declared.}

This article has been peer reviewed.

The authors have obtained parental consent.
Affiliations: Division of Neonatology, Department of Pediatrics (Lopez); Lions Gate Hospital (Lopez); Departments of Pediatrics and Dermatology \& Skin Science (Lam), University of British Columbia, Vancouver, BC

Correspondence to: Joseph Lam, joseph.mc.lam@gmail.com 